\title{
Knowledge of Hypertension Among Adults in Owerri Senatorial Zone of Imo State, Nigeria
}

\author{
Onyekwere Ogechi Kate, Ezebuiro Veronica Okwuchi and E. S. Samuel
}

Department of Health and Physical Education, University of Nigeria, Nsukka-Nigeria

\section{Doi:10.5901/mjss.2013.v4n5p69}

\begin{abstract}
The study was conducted to ascertain knowledge of hypertension among adults in Owerri senatorial zone of Imo state, Nigeria. Three specific objectives were formulated with three corresponding research questions. The only null-hypothesis was also postulated to guide the study. Descriptive survey research design was used and the sample consisted of 432 adults. Questionnaire was the instrument for data collection. Percentages and ANOVA were used to analyze the data. The results of the study showed that adults had high level of knowledge of the concept and risk factors of hypertension. There was significant difference in the level of knowledge of hypertension among adults according to level of education. The study therefore recommends that government and voluntary health agencies should sponsor intensive enlightenment campaign through print and electronic media in order to sustain the knowledge level of adults on hypertension.
\end{abstract}

Keyword: Knowledge, Hypertension, Adults, Risk factors.

\section{Introduction}

Hypertension remains a major global public health challenge that has been identified as the leading risk factor for cardiovascular morbidity and mortality (Kearney, Whelton, Reynolds, Muntner, Whelton \& He, 2004). It increases hardening of the arteries, thus predisposing individuals to heart diseases, peripheral vascular diseases, stroke, heart failure and kidney failure. Castelli (2004) explained that its prevalence is on the increase in developing countries where adoption of western lifestyle and stress of urbanization, both of which are expected to increase morbidity associated with unhealthy lifestyle are not on the decline. Andreoli, Carpenter, Grigs and Loscalzo (2004) was of the opinion that hypertension produces disruptions in health, disability and death in the adult population worldwide. Ejike, Ezeanyika and Ugwu (2010), stated that hypertension causes one in every eight deaths worldwide, making it the third leading killer disease in the world. They also estimated that about one billion adults, the world over, had hypertension in the year 2010 and the number is expected to rise to 1.56 billion in the year 2025.

In the United States of America, approximately twenty eight to thirty one per cent of adults have hypertension (Fields, Burtler \& Cutler, 2004). In China, almost 130 million people aged 35-74 years are estimated to be hypertensive (Camele \& Delene, 2006). In sub-Saharan Africa, it is the most rapidly rising cardiovascular disease and affecting over 20 million people (Kadiri, 2005). He also maintained that in Nigeria, hypertension is the commonest non-communicable disease with over 4.3 million Nigerians above the age of fifteen years classified as being hypertensive.

Hypertension, also known as high blood pressure is the persistent blood pressure in the arteries above ninety millimeters of mercury $(\mathrm{mmHg}$ ) between the heart beats (diastolic) or over 140 millimeters of mercury ( $\mathrm{mmHg}$ ) at the beats (systolic). According to Hyman and Parlik (2003), hypertension is the persistent raised levels of blood pressure in which the systolic pressure is above $140 \mathrm{mmHg}$ and diastolic pressure above 90 $\mathrm{mmHg}$. The normal blood pressure is below 120/80 mmHg; blood pressure between 120/80 and 139/89 is called 'Pre-hypertension, and a pressure of $140 / 90$ or above is considered high (abnormal) blood pressure. 
According to Expert Committee on Non-Communicable Diseases (1993), blood pressure of $120 / 80 \mathrm{mmHg}$ is considered normal for a 30 year old person, while blood pressure of $140 \mathrm{mmHg}$ is considered high for such a person. Similarly, blood pressure of $150 / 90 \mathrm{mmHg}$ is considered normal for a 60 -year old person, while blood pressure of $160 / 100 \mathrm{mmHg}$ is high for such a person. Hypertension is sometimes called "the silent killer" because people who have it are often symptom-free. In this study, hypertension is perceived as a systolic blood pressure greater than $140 \mathrm{mmHg}$ and a diastolic blood pressure greater than $90 \mathrm{mmHg}$ among adults. The top number which is the systolic pressure corresponds to the pressure in the arteries as the heart contracts and pumps blood forward into the arteries. The bottom number which is the diastolic pressure represents the pressure in the arteries as the heart relaxes after contraction. The diastolic pressure reflects the lowest pressure to which the arteries are exposed. Blood pressure is normally measured at the brachial artery with a sphygmomanometer (pressure cuff) in millimeters of mercury (mmhg) and given as systolic over diastolic pressure. Hypertension is classified into two groups.

According to Stanler (2004), hypertension is classified into primary and secondary hypertension. Primary hypertension has an unknown cause and accounts for ninety per cent to ninety five per cent of all hypertension cases (Chris, 2009). This type of hypertension is strongly associated with lifestyle. Usually, the patients do not have many signs and symptoms but may experience frequent headache, tiredness, dizziness or nose bleeds. Although the cause is not known, obesity, smoking, alcohol, diet and heredity play a role in essential or primary hypertension.

Secondary hypertension has a known cause and accounts for five per cent to ten per cent of all hypertension cases. Chris (2009) maintained that the most common cause of secondary hypertension is an abnormality in the arteries supplying blood to the kidneys. Other causes include airway obstruction during sleep, stress, diseases and tumors of the adrenal glands, lifestyle, spinal cord injury, hormone abnormalities (oral contraceptive estrogen replacement), thyroid disease, toxemia of pregnancy, renal problems such as vascular lesion of renal arteries, diabetic neuropathy, pains as well as anxiety and hypoglycemia. There are some factors which predispose adults to hypertension.

Jones, Dumber and Jirovec (2003) identified several factors which predispose individuals to hypertension. Such factors are genetic factors, age, obesity, excess salt intake, cigarette smoking, environmental stress, oral contraceptives, sedentary lifestyle, elevated levels of plasma lipids and unregulated secretion of aldosterone. There are risk factors that can be modified and those that can not be modified. Modifiable (behavioral) risk factors are determinants that can be changed or modified by intervention, thereby reducing the probability of hypertension disease. These lifestyle factors can be controlled. Forman, Meir and Curhan (2009) posited that many modifiable risk factors for hypertension have been identified, including overweight or obesity, physical inactivity, and having a poor diet. Excessive alcohol consumption, tobacco smoking, high blood cholesterol, high salt intake and stress are all modifiable risk factors of hypertension.

Obesity is an increase in weight of over 10 per cent above normal body index due to generalized deposition of fat in the body. Onuzulike (2006) asserted that excess weight promotes hypertension and lipid abnormalities. It predisposes the individual to diabetics which in turn accelerates to coronary artery disease and increases the risk of stroke. Dischuneit, Flechner, Johnson and Adler (2006) asserted that physical inactivity coupled with obesity seem to have more implication in hypertension than obesity alone.

Excess salt intake has been implicated in hypertension. Chhabra, Lal and Sharma (2002) observed in a study that a high salt intake of about 7-8grarm a day increases blood pressure proportionately. Chemically, salt is made of sodium and chloride. Sodium is of higher concentration than water, thus, can easily draw water from the surroundings to dilute itself. This explained why salt that is left over night on a table becomes water the following morning. This same phenomenon takes place inside the blood vessels. They further explained that if the salt concentration of blood is high, water from the surrounding cells move into the blood vessels to dilute the salt. When this happens, the volume of the blood increase with corresponding increase in volume of blood in the heart which increase the pressure with which blood flows through the blood vessels. 
Org, Cheung, Man, Lau and Lam (2007) acknowledged that diets high in salt and saturated fats have been shown to be etiologically related to hypertension. Foods that fit into this category include canned foods, bacon, frozen foods, hot dogs, ham, salted nuts, sausages, seasoning salt, salted cheese and potato chips. Other foods that contribute to risk of hypertension include fat sources of all kinds namely, butter, eggs, red fatty meat, ice cream and cheese. Furthermore, it is not advisable to add table salt to ones food.

Erhum, Olayiwola, Agbani and Omtoso (2005) stressed that cigarette and tobacco smoking as an unhealthy social habit has short-circuited millions of lives for many countries, and is one of the root causes of chronic diseases of which hypertension is one of them. According to them, cigarette is a suicide bomber seeking for a person whose health and life will blow away with its smoke. Cigarette contains nicotine, which causes contraction of the blood vessels (vasoconstriction) that can lead to hypertension, stroke and cardiac output. Blood pressure rises and the heart also has to work harder to pump increased volumes of blood through damaged lungs. Onuzulike (2006) contributed that smoking nicotine and carbon monoxide from tobacco have been found to provoke increased level of adrenalin and this causes narrowing of the arterioles leading to increase in blood pressure.

Stress is a risk factor of hypertension which activates the autonomic nervous system and of the central nervous-pituitary adrenalin system. Andreoli, Carpenter, Griggs and Loscalzo (2004) explained that during stress or emotional disturbances, the body system produces chemical substances called catecholamine and adrenalin. These substances when released cause generalized vasoconstriction (contraction) and narrowing of the blood vessels, which can produce transient hypertensive state. Oral contraceptives such as estrogen preparations can precipitate or aggravate hypertension which usually is reversed when this medication is discontinued.

Sedentary lifestyle as a risk factor of hypertension elevates blood pressure. Org, et al. (2007) explained that lack of physical fitness especially cardiovascular fitness derived from aerobic exercise is known to be related to elevated blood pressure. The role of exercise in the sustenance of the natural supple condition of the arteriole cells and influencing favourable ratios of low density lipoproteins to the high-density variety is critical in the development and progression of hypertension. Regular exercise lowers blood stimulating metric oxide (helps keep blood vessels open). Elevated levels of plasma lipids particularly cholesterol and triglycerides have been found to be closely related to the development of hypertension (Burt, Cutler \& Higgins, 2004). When there is excess fat in the body, the ability of the enzyme (lipase) to break down the fats is overwhelmed thereby leading to accumulation of excess fat in the cells, a disorder called cholesterol storage disease.

There are some contraceptive pills which prevent pregnancy, and are associated to the risk of developing hypertension. Castelli (2004) stated that the main ingredient of these contraceptive pills (oestrogen) cause increased hepatic secretion of rennin substance, which in turn increases the formation of anquitensine. This substance enhances re-absorption of sodium (salt) from the kidney which means that estrogen causes salt retention. By direct an indirect retention of salt, eostrogen increases the volume of blood in the heart and the quantity it pumps into the circulation with the attendant increase in blood pressure.

High alcohol consumption is associated with an increased risk of hypertension. Onuzulike (2006) explained that risk of hypertension has been raised among heavy alcohol drinkers. She further explained that in some of larger population based surveys, the role of regular alcohol intake in the development of cerebrovascular episodes has been examined and most of results showed that there is a positive association. These factors are more pronounced during adulthood, and knowledge of the risk factors of hypertension is an important step in the modification of lifestyle behaviours conducive for optimal cardiovascular health.

The non-modifiable risk factors of hypertension are those factors which cannot be controlled and changed but awareness of these risk factors is important for prevention. Such factors are genetic predisposition, age, and gender. The tendency of developing essential hypertension has long been recognized to run in families (genetic predisposition). Those who have family history of this health problem are more prone to be hypertensive than those who do not, for example, if a person has relatives with high 
blood pressure, his chances of suffering from the disease is greater. Thatch \& Schutz (2004) observed that about 75 per cent of hypertensive patients have a family history of hypertension. Onuzulike (2006) contributed that if both parents have hypertension, there is every tendency that some of the offspring's may be predisposed to it.

Age is also a non-modifiable risk factor of hypertension. The incidence of hypertension has been said to rise with age. Mandal, Roy, Chitra, Mallik, Manna, Sadar, Debadatta and Sau (2010) supported this by stating that the level of intimacy for blood pressure varies according to age. As the body gets older naturally, it does not retain the amount of elasticity as it used to during early years of life. The arteries become hard and this increases the resistance to blood flow and the older a person becomes, the more he or she is likely to be hypertensive. This is because hypertension becomes prevalent with increasing age, most likely because of reduced arterial compliance or blood flow. When both parents are involved, the risk is especially great. However, if the onset of hypertension occurs during the younger ages, life expectancy of the individual decreases and even a modest elevation of blood pressure are associated with a great increased risk of death (Gaudemaris, Lang, Chaltellier, Larabi, Lauwers, Maitre \& Diene 2002). These risk factors are modified by lifestyle changes. Furthermore, as the heart develops over the years, adults need to be aware of the modifiable risk factors in order to follow healthy lifestyle practices and reduce their chances of morbidity.

Gender is one of the non-modifiable risk factors of hypertension. The frequency of hypertension is greater in men than women up to about the age fifty years, but the reverse is the case at older ages. Although the risk of developing hypertension is higher in older women as compared with older men, the probability of developing a stroke is directly related to the systolic blood pressure regardless of gender and age. Rahman, Douglas and Wright (2004) explained that after menopause, the incidence of hypertension disease due to arteriosclerosis in woman rapidly approaches than in men. Women are seen to have more incidence of hypertension due to the disappearance of female stronger hormone which provides effect against heart disease and high blood pressure. These non-modifiable risk factors of hypertension can not be changed but awareness of the risk factors is important for prevention. Preventing these risk factors will have a significant impact in the morbidity rates to acceptable level. Knowledge of hypertension risk factors is essential for an adult to make an informed decision about preventing hypertension.

There are many variables that may impinge on knowledge of hypertension. Literature shows that studies on knowledge of hypertension examined socio-demographic factors of age, race, level of education, parity, gender, income, location, occupation and marital status (Hamdan, Saeed, Kutbi, Choudhry and Nooh, 2010). However the present study was concerned with demographic factor of level of education.

Studies have indicated that level of education is associated with knowledge, which may include the risk factors and preventive measures of hypertension. According to Ali and Jimoh (2011) in a study on Knowledge of hypertension among the staff of university of Ibadan, Nigeria observed that reported that level of education significantly influences awareness of complications and knowledge of risk factors of hypertension. The higher the educational attainment, the higher the acquisition of knowledge, attitude and behaviour, while the lower the level of education, the lower increase in knowing risk factors and prevention measures of hypertension. similarly, Myo, Thaworn, Janthila, Nongluk, Suchart, Wilawan, Phatchanan, Puangpet, Nara and Apiradee (2012) in a study on assessing awareness and knowledge of hypertension in an at-risk population in the Karen ethnic rural community, Thasongyang, Thailand, reported that those with primary school education were likely to be aware of hypertension than those who did not have primary school education. Similarly, the findings of Derakhshan, Shaihin, Fateme, Sabet and Hamid (2006) in a study to determine the knowledge of pregnancy induced hypertension in Iranian pregnant women and the effect of a simple educational interventionalmeasurereportedthatthelevelofknowledgeandattitudeofpregnantwomenincreasedsignificantlyaft ereducation.

Owerri senatorial zone is in Imo state located in the South Eastern part of Nigeria. The senatorial zone covers around 1,700sqkm and shares common boundaries with Abia State by the east, and Rivers State by the south. The inhabitants are engaged in agriculture, businesses and civil service works. These activities 
occupy much of their time with little or no time left for them to have rest and take care of their health, and they undergo lots of stress which can lead to hypertension. Furthermore, there are places which serve as tourist attractions in the zone such as Mbari exhibition centre, Imo Concorde hotel and lots of hotels and guest houses where people come for relaxation. These places expose adults to excessive alcohol consumption. Additionally, the diverse in culture play an important role in the knowledge of adults regarding hypertension. Some cultures in the senatorial zone believe that once alcohol is taken, nothing else matters, and this drinking style (unhealthy lifestyle) exposes adults to hypertension which has its consequences. This location was picked for the study because of its peculiar mixed culture which in many ways has profound influence on adults' health.

Despite effective therapies and lifestyle interventions, optimal prevention of hypertension remains a very health challenge to health professionals especially in most developing countries like Nigeria. Kadiri (2005) noted that 4.3 million Nigerians are suffering from this silent killer disease called hypertension. The inability to adequately prevent or manage hypertension in Nigeria can be attributed to inadequate knowledge of hypertension. Thus reaching the healthy people vision 2020 objective may be difficult if necessary actions are not taken to prevent this disease. If health promotion programmes are to be appropriate and effective, adults' knowledge of hypertension need to be identified. The identification of gaps in adults' knowledge of hypertension is capable of aiding the development of adequate information to enhance the knowledge of hypertension.

Unfortunately, most adults due to ignorance of knowledge of hypertension engage in unhealthy lifestyles such as excessive consumption of alcohol, sedentary lifestyle, excess consumption of sodium intake, tobacco and cigarette smoking, obesity, reduced intake of fruits and vegetables, stress and consumption of foods rich in cholesterol. These unhealthy lifestyle practices have increased the prevalence of hypertension in the world including Nigeria, which culminates into high cases of deaths. Hypertension is one of the problems affecting especially a great portion of the adult population and currently causes one in every eight deaths worldwide, making it the third leading killer disease intheworld. Inaddition,hypertensionis the commonest non-communicablediseaseinNigeriawithover4.3millionNigerians classified as being hypertensive.In Nigeria, many people lose their lives to hypertension. This is not an acceptable situation, considering the fact that hypertension is preventable and manageable to reduce its impact on the health and lives of people in Nigeria.

However, some studies have been conducted on the knowledge of hypertension in many parts of the world including Nigeria. Incidentally, there are no studies, to the best knowledge of the researchers that seems to have been carried out in Owerri Senatorial Zone of Imo state to determine the level of knowledge of hypertension among adults. In view of the above, the need arose to determine if adults in Owerri senatorial zone of Imo state have adequate knowledge of hypertension. This was the task of the present study.

\section{Purpose of the Study}

The purpose of the study was to determine the level of knowledge of hypertension possessed by adults in Owerri Senatorial Zone of Imo State. Specifically, the study was set to determine the level of knowledge of:

1. concept of hypertension possessed by adults;

2. risk factors of hypertension possessed by adults and

3. hypertension possessed by adults according to level of education?

\section{Research Questions}

The following research questions were posed to guide the study.

1. What is the level of knowledge of the concept of hypertension possessed by adults?

2. What is the level of knowledge of risk factors of hypertension possessed by adults? 
3. What is the level of knowledge of hypertension possessed by adults according to level ofeducation?

\section{Hypothesis}

1. There is no significant difference in the level of knowledge of hypertension possessed by adults according to level of education.

\section{Methods}

The research design was a descriptive survey research design. The population for the study consisted of 355,453 adults in Owerri senatorial of Imo state. A multi-stage sampling procedure was used to draw a sample of 432 adults in the senatorial zone. The sample was done in five stages. Stage one involved random selection of six local governments from the nine existing local governments in Owerri senatorial zone of Imo state. The second stage involved stratification of the local governments into urban and rural areas. The third stage involved simple random of balloting with replacement to select two autonomous communities giving a total of twelve autonomous communities. The forth stage involved purpose selection of two villages each from the twelve selected autonomous communities giving a total of twenty four villages. The last stage involved systematic selection of eighteen households each from the twenty four selected villages making a total of four hundred and thirty two households. One adult above the age of thirty five years old and who was the first to be reached in each household constituted the sample. The instrument for data collection was the researchers' structured questionnaire on knowledge of hypertension questionnaire (KHAAQ). It had three sections. Section A was concerned with the bio-data of the respondents, section B consisted of six questions on the concept of hypertension while section $C$ comprised of nine questions on risk factors of hypertension based on the objectives of the study. The instrument was validated by five experts from the department of Health and Physical education, University of Nigeria, Nsukka. The modification of the instrument was based on the judgment of the experts. Split-half method using Cronbach Alpha statistic was used to establish the internal consistency of the instrument. The validated instrument was administered by the researchers and three research assistants on face to face basis to the respondents. Data collected was analyzed using the Statistical Package for Social Science (SPSS) batch system The generated data were presented in tables using Ashur's (1977) criteria for describing level of knowledge were utilized for answering the research questions. According to the scale, a proportion of less than 40 per cent is considered "low level of knowledge; 41-59 per cent is "average knowledge; 60-80 per cent is "high" level of knowledge and above 80 per cent is considered "very high" level of knowledge. ANOVA statistic was used to test the only null hypothesis at .05 level of significance and appropriate degrees of freedom.

\section{Results}

Table 1: Level of knowledge of Adults Regarding the Concept of Hypertension - KCH ( $n=408)$

\begin{tabular}{ccc}
\hline Dimensions & $\mathbf{n}$ & $(\bar{X} \%)$ \\
\hline Knowledge of the Concept of Hypertension $(\mathrm{KCH})$ & 408 & 64.60 \\
\hline
\end{tabular}

Data in Table 1 above show a mean score of 64.60 per cent which fell between $60-80$ per cent. This implies that the level of knowledge of adults regarding the concept of hypertension was high. 
Table 2: Level of knowledge of Adults Regarding the Risk Factors of Hypertension - KRFH ( $n=408)$

\begin{tabular}{ccc}
\hline Dimensions & $\mathbf{N}$ & $(\bar{X} \%)$ \\
\hline Knowledge of Risk Factors of Hypertension (KRFH) & 408 & 61.73 \\
\hline
\end{tabular}

Table 2 shows a mean score of 61.73 per cent which fell between $60-80$ per cent. This implies that the level of knowledge of adults regarding the risk factors of hypertension was high.

Table 3:Level of knowledge of Adults Regarding Hypertension by According to Level of Education

\section{Level of Education}

\begin{tabular}{lcrccc}
\hline & & \multicolumn{5}{c}{ Level of Education } \\
\hline \multirow{3}{*}{$\mathrm{S} / \mathrm{n}$} & \multirow{2}{*}{$\begin{array}{c}\text { No formal } \\
\text { Education } \\
(\mathrm{n}=20)\end{array}$} & $\begin{array}{c}\text { Primary } \\
\text { Education } \\
(\mathrm{n}=32)\end{array}$ & $\begin{array}{c}\text { Secondary } \\
\text { Education } \\
(\mathrm{n}=102)\end{array}$ & $\begin{array}{c}\text { Tertiary/University } \\
\text { Education } \\
(\mathrm{n}=254)\end{array}$ \\
\hline 1. & $\mathrm{~K} \%$ & $\bar{X} \%$ & $\bar{X} \%$ & $\bar{X} \%$ \\
\hline 2. & $\mathrm{KCH}$ & 48.50 & 47.41 & 60.48 & 69.69 \\
& $\mathrm{KRFH}$ & 53.90 & 45.47 & 56.49 & 66.50 \\
\hline
\end{tabular}

Key

$\mathrm{KCH}$ - Knowledge of Concept of Hypertension

$\mathrm{KRFH}$ - Knowledge of Risk Factors of Hypertension

Table 3 show that the mean score of adults with tertiary education $(\bar{X}=69.69 \%)$ was slightly higher than those with secondary education ( $\bar{X}=60.48 \%$ ), without formal education ( $\bar{X}=48.50 \%$ ) and those with primary education $(\bar{X}=47.41 \%$ ). This implies that adults with tertiary/university and secondary education had high level of knowledge while adults without formal education and primary education possessed moderate level of knowledge regarding the concept of hypertension.

Table 3 further shows that the mean score of adults with tertiary education ( $\bar{X}=66.50 \%$ ) was higher than those with secondary education ( $\bar{X}=56.49 \%)$, primary education $(\bar{X}=45.47 \%$ ) and those with no formal education ( $\bar{X}=53.90 \%)$. This implies that adults with tertiary education

possessed high level of knowledge while adults with secondary education, primary education and those with no formal education had moderate level of knowledge regarding the risk factors of hypertension.

Table 4: Result of One-Way Analysis of Variance (ANOVA) Testing the Null Hypothesis of no Significant Difference in the Level of Knowledge of Hypertension according to Level of Education.

\begin{tabular}{|c|c|c|c|c|c|c|c|}
\hline $\begin{array}{c}\text { Dimensions } \\
\text { of } \\
\text { Hypertension }\end{array}$ & $\begin{array}{c}\text { Sum Within } \\
\text { Groups }\end{array}$ & $\begin{array}{c}\text { Sum } \\
\text { Between } \\
\text { Groups }\end{array}$ & df & $\begin{array}{c}\text { Mean } \\
\text { Between } \\
\text { Groups }\end{array}$ & $\begin{array}{c}\text { Mean } \\
\text { Within } \\
\text { Groups }\end{array}$ & F & P-value \\
\hline $\mathrm{KCH}$ & 22963.450 & 202194.227 & 3 & 7654.483 & 500.481 & 15.294 & $.000^{*}$ \\
\hline $\mathrm{KRFH}$ & 18267.584 & 205400.759 & 3 & 6089.195 & 508.418 & 11.977 & $.000^{*}$ \\
\hline
\end{tabular}

*significant at .05 level. 
Table 4 shows that the F-value for $\mathrm{KCH}(15.294, \mathrm{P}=.000<.005)$ and $\mathrm{KRFH}(\mathrm{F}=11.977, \mathrm{P}=.000<$ $.05)$ are less than .05 level of significance and at 3 and 404 degrees of freedom. The null hypothesis of no significant difference was therefore rejected. This implies that adults differed in their level of knowledge of the concept and risk factors of hypertension according to their level of education. Scheffe's test was prepared to determine the specific educational dispositions of the adults that contributed to the observed differences as shown in Table 5.

Table 5: Scheffe's Post- Hoc Analysis of Group Mean Scores Based on Level of Education of Knowledge of Hypertension

\begin{tabular}{|c|c|c|c|c|}
\hline $\begin{array}{l}\text { Dimensions of } \\
\text { Hypertension }\end{array}$ & Level of Education (I) & Level of Education (J) & $\begin{array}{c}\text { Mean Difference } \\
(\mathrm{I}-\mathrm{J})\end{array}$ & P-value \\
\hline \multirow[t]{12}{*}{$\mathrm{KCH}$} & \multirow[t]{3}{*}{ No formal Education } & \multirow{3}{*}{$\begin{array}{l}\text { Primary education } \\
\text { Secondary education } \\
\text { Tertiary/University } \\
\text { education }\end{array}$} & 1.094 & .999 \\
\hline & & & -11.980 & .189 \\
\hline & & & $-21.193^{*}$ & .001 \\
\hline & \multirow[t]{3}{*}{ Primary education } & \multirow{3}{*}{$\begin{array}{l}\text { No formal education } \\
\text { Secondary education } \\
\text { Tertiary/University } \\
\text { education }\end{array}$} & -1.094 & .999 \\
\hline & & & $-13.074^{\star}$ & .041 \\
\hline & & & $-22.287^{\star}$ & .000 \\
\hline & \multirow[t]{3}{*}{ Secondary education } & \multirow{3}{*}{$\begin{array}{l}\text { No formal education } \\
\text { Primary education } \\
\text { Tertiary/University } \\
\text { education }\end{array}$} & 11.980 & .189 \\
\hline & & & $13.074^{*}$ & .041 \\
\hline & & & $-9.213^{*}$ & .007 \\
\hline & \multirow[t]{3}{*}{ Tertiary/University education } & No formal education & $-21.193^{*}$ & .001 \\
\hline & & Primary education & $22.287^{\star}$ & .000 \\
\hline & & Secondary education & $9.213^{*}$ & .007 \\
\hline \multirow[t]{12}{*}{$\mathrm{KCH}$} & \multirow[t]{3}{*}{ No formal Education } & \multirow{3}{*}{$\begin{array}{l}\text { Primary education } \\
\text { Secondary education } \\
\text { Tertiary/University } \\
\text { education }\end{array}$} & 8.431 & .633 \\
\hline & & & -2.590 & .974 \\
\hline & & & -12.600 & .124 \\
\hline & \multirow[t]{3}{*}{ Primary education } & \multirow{3}{*}{$\begin{array}{l}\text { No formal education } \\
\text { Secondary education } \\
\text { Tertiary/University } \\
\text { education }\end{array}$} & -8.431 & .633 \\
\hline & & & -11.021 & .123 \\
\hline & & & $-21.031^{*}$ & .000 \\
\hline & \multirow[t]{3}{*}{ Secondary education } & \multirow{3}{*}{$\begin{array}{l}\text { No formal education } \\
\text { Primary education } \\
\text { Tertiary/University } \\
\text { education }\end{array}$} & 2.590 & .974 \\
\hline & & & 11.021 & .123 \\
\hline & & & $-10.010^{*}$ & .003 \\
\hline & \multirow[t]{3}{*}{ Tertiary/University education } & No formal education & 12.600 & .124 \\
\hline & & Primary education & $21.031^{*}$ & .000 \\
\hline & & Secondary education & $10.010^{*}$ & .003 \\
\hline
\end{tabular}

*The mean difference is significant at .05 . 
Table 5 presents the mean differences from the paired mean comparison of the four educational levels of adults with regard to the level of $\mathrm{KCH}$ and $\mathrm{KRFH}$. The table shows that all the levels of education with asterisks show significant difference since their p-values are less than .05 level of significance while those without asterisks primary education and no formal education (mean difference $=1.094$, p-value $=.999$ ) and secondary and no formal education (mean difference $=11.980, p$-value $=.189$ ) show there is no significant difference in the knowledge of adults regarding the concept of hypertension.

The table further reveals that all the levels of education with asterisks show significant difference while primary and no formal education (mean difference $=-8.431, p$-value $=.633$ ), secondary and no formal education (mean difference $=-2.590, \mathrm{p}$-value $=.974)$, tertiary/university and no formal education (mean difference $=-12.600, p$-value $=.124)$ and secondary and primary education (mean difference $=-11.021, p$ value $=.123$ ) without asterisks show there is no significant difference in the knowledge of adults regarding risk factors of hypertension.

\section{Discussion}

Results in Tables 1 and 2 revealed that adults in Owerri Senatorial Zone possessed high $(\bar{X}=64.60 \%)$ level of knowledge regarding the concept of hypertension and risk factors of hypertension $(\bar{X}=61.73 \%)$. The finding was expected and therefore not surprising. This is because adults might have been attending seminars, workshops and conferences where hypertension is being discussed. Besides, adults in Owerri senatorial zone might also be educated and their level of education can enhance their knowledge of health matters including hypertension. This finding is in consonance with the findings of Ali and Jimoh (2011) who reported in their study that some members of staff demonstrated a relatively high level of knowledge about the complications associated with hypertension but knowledge about the risk factors of hypertension and attitude towards the illnesswas still low.

Result in Table 3 showed that adults' with no formal education had moderate level of knowledge of hypertension while adults with primary education possessed moderate level of knowledge of risk factors of hypertension (KRFH). Furthermore, adults with secondary education possessed moderate level of knowledge of hypertension while adults with tertiary/university education possessed high level of knowledge of hypertension. This finding is, however, not surprising and expected. It is expected that adults with university/tertiary and secondary education should exhibit high level of knowledge while adults with primary and no formal education should possess low level of knowledge of hypertension. This is because; experience has shown that educated adults tend to avail themselves with health awareness programmes thereby exhibiting high knowledge. In addition, the information they have on healthy lifestyles and health issues in school could help them embrace positive attitude towards hypertension. This finding is in consonance with the findings of Ali and Jimoh (2011) which reported that level of education significantly influenced awareness of complications and knowledge of risk factors of hypertension.

Result in Table 4 indicated that there was significant difference in the level of knowledge of hypertension according to level of education. This finding was anticipated and therefore, not a surprise. Educational level of any given group of individuals is expected to influence their knowledge of a given health concept or behaviour. This is because adults with high educational attainments are expected to exhibit adequate and high knowledge of the dimensions of hypertension. It is a well established fact that education stimulates and empowers an individual's intellectual capacity to understand concepts especially when such concepts are concretized. This finding is in consonance with that of Myo, Thaworn, Janthila, Nongluk, Suchart, Wilawan, Phatchanan, Puangpet, Nara, and Apiradee (2012) findings which reported that those with primary school education were likely to be aware of hypertension than those who did not have primary school education. Scheffe's test (Table 5) indicated that tertiary/university education had higher mean difference for knowledge of the concept and risk factors of hypertension according to level of education. This agrees with the findings of Ali and Jimoh (2011) which reported that level of education significantly influences 
awareness of complications and knowledge of risk factors of hypertension. Similarly, the findings of Derakhshan,Shaihin, Fateme, Sabet and Hamid (2006) reported that thelevelofknowledge andattitude ofpregnantwomenincreasedsignificantlyaftereducation.

\section{Conclusions}

From the findings of the study, the following conclusions were drawn;

1. Adults' had high level of knowledge regarding the concept of hypertension $(\mathrm{KCH})$.

2. Adults' had high level of knowledge regarding risk factors of hypertension (KRFH).

3. Adults with no formal education had moderate level of knowledge in the concept and risk factors ofhypertension while adults with primary education possessed moderate level of knowledge for $\mathrm{KCH}$ andKRFH. Furthermore, adults withsecondary education possessed moderate level of knowledge of the concept and risk factors of hypertension while adults withtertiary/university education possessed high level of knowledge in the concept and risk factors ofhypertension.

4. There was significant difference in the level of knowledge of the concept and risk factors of hypertension among adultsaccording to level of education. Scheffe's test analysis revealed that adults withtertiary/university education had highersignificantdifference in the level of knowledge of the concept and risk factors of hypertension among the levels ofeducation.

\section{Recommendations}

Based on the findings, discussions and conclusions of the present study, the following recommendations were made:

1. Government and voluntary health agencies should sponsor intensive enlightenmentcampaign through print and electronic media in order to sustain the knowledge level of adults on hypertensionand its complications.

2. Non-governmental organizations such as religious organizations and social clubs as well as village meetings should organize seminars, health talks, conferences and workshops to members towards sensitizing and enlightening them on the health effects of hypertension and should as well educate them on those factors which can predispose them to theillnessesand ways to combat them.

\section{References}

Ali, A. B. \& Jimoh, A. (2011). Knowledge of hypertension among the staff of university of Ibadan,Nigeria. Journal of Public Health and Epidemiology 3 (5) 204-209

Andreoli, T. E, Carpenter, C. C., Grigs, R. C. \& Loscalzo, J. (2004). Hypertension: Cecilessentials of medicine (3rd Ed). Pennsylvania: Saunders

Ashur, S. S. (1977). An evaluation plan for the development and up-dating of nutritioncurriculum of the upper elementary and preparatory levels in Jordan. NES/

Burt, V. L. Cutter, I. A. \& Higgins, M. (2004). Trends in the prevalence, awareness, in the adult United States population: Data from the Health examination surveys, 1960 -1991. Journal of Hyperteens (26) 60-69.

Camel, L. \& Delen, B. (2006). Myles textbook for midwives (14th Ed). New York: Churchill Livingstone.

Castelli, W. P. (2004). Epidemiology of coronary heart disease. The Framingham Study. American Journal of Medicine (76) $4-12$.

Chhabra, M. K., Lal, A. \& Sharma, K. K. (2002). Status of lifestyle modifications in hypertension: Journal of Indian Medical Association 99 (6) $504-508$.

Chris,L.(2009).Differenttypesofhypertension.Retrievedfrom http://www.everydayhealth.com/health-center/high-bloobpressure. Accessed on 03/02/2012. 
Derakhshan, E., Shahin, S., Fatema, D., Babak, S., Roya, D. \& Hamid, R. A. (2006). The knowledge of the pregnancy induced hypertension in Iranian pregnant women and the effect of a simple educational interventional measure. International Medical Journal 5 (1) 258-266.

Dischuneit, H.H., Flechner, M., Johnson, T.D., \& Adler, G. (2006). Metabolic and weight loss effects of a long term dietary intervention in obese patients. Am J. Chin Nutr. 69(6)198-204.

Ejike, C. C., Ezeanyika, L. U. \& Ugwu, C.E. (2010). Variations in the prevalence point of pre-hypertension in a Nigeria school - going adolescent population living in Auchi, Nigeria. BMC Pediatrics 10 (13) 1471 - 2431.

Erhum, W. O., Olayiwola, G., Agbani, E. O., \& Omtoso, N. S. (2005). Prevalence of hypertension in a University community in South West, Nigeria. African Journal of Biomedical Research, 8, 15-19.

Expert Committee on Non-Communicable Diseases (1993). What should we conclude in the absence of data. Nigeria: Lancelot medicine.

Fields, L. E., Burt, V. L., \& Cutler, J. A. (2004). The burden of adult hypertension in the United States 1999 - 2002: A rising tide, hypertension. The Lancelot, 44 (4) $398-404$.

Forman, J., Meir, W. \& Curhan, Z. (2009). Diet and lifestyle risk factors associated with incident hypertension in women. Journal of American Medical Association, 302 (4) 401-411.

Gaudemaris, R. D., Lang, T., Chatellier, G., Labari, L., Lauwers, C. V., Maitre. A. \& Diene, E., (2002). Socio-economic inequalities in hypertension prevalence and care. The IHPAI Study, 39(6) $1119-1125$.

Hamdan, N. A., Saeed, A., Kutbi, A., Choudhry, A. J. \& Nooh, R., (2010). Characteristics, riskand treatment practices of known adult hypertensive patients in Saudi Arabia: International Journal f Hypertension, 10 (2) 4061 -4075.

Hyman, D. J., \& Parlik, V. N. (2003). Characteristics of patients with uncontrolled hypertension in the United States of America. New England Journal of Medicine, 345 (7) 489 - 496.

Jones, D. A, Dumber, C. F, \& Jirovec, M. M. (2003). Medical-surgical nursing: A conceptual approach. McGraw-Hill Kaqakusha Ltd. International Student Edition 936-737.

Kadiri, O. (2005). Blood pressure, hypertension and correlates in urbanized workers in Ibadan, Nigeria. A revisit. Journal of Human hypertension, 13 (7) 23-27.

Kearney, P. M., Whelton, M., Reynolds, K., Muntner, P., Whelton, P. K., He, J., (2004). Global burden of Hypertension: Analysis of Worldwide Data. Journal of Hypertens, 22(1)140.

Mandal, P. K., Roy, A. K. S., Chitra, C., Mallik, S., Manna, N., Sadar, J. C., Debadatta, C. \& Sau, M. (2010). Burden of hypertension and its risk factors in an urban community of India: Are we aware and concerned. Sundanese Journal of PublicHealth, 5(3) 130-135.

Myo, N. A. , Thawom, L. , Janthila, S. , Nongluk, P. , Suchart, K. , Wilawan, T. , Phatchanan, V., Puangpet, J. Nara, P. \& Apiradee, P. (2012). Assessing awareness and knowledge of hypertension in an at-risk population in the Karen ethnic rural community, Thasongyang, Thailand. International Journal of General Medicine, 5(1)553-561.

Onuzulike, M. N. (2006). Issues in Health Education ( $3^{\text {rd }}$ Ed). Owerri: Mc Williams.

Org, K.L., Cheung, B. M., Man, Y. B., Lau, C. P. \& Lam, K. S. (2007). Prevalence, awareness, treatment and control of hypertension among United states of American adults. Pub Med ISI Chem port. 237(3)255-261.

Rahman, M., Douglas, J. G., \& Wright, J. T., (2004). Pathophysiology and treatment implications of hypertension in the African-American population. Clin North Am Journal, 26(1)125-144.

Stanler, R. (2004). The primary prevention of hypertension and the population blood pressure problem: Coronary heart disease epidemiology: From etiology to publichealth. New York: Oxford University Press.

Thatch, A. M. \& Schutz, P. I. (2004). Non-emergent hypertension. Emerg med clin NorthAmerica, (13) 1009-1010

Winham, D. M. \& Jones, M. (2011). Knowledge of young Americans about hypertension. BMC journalof public Health,10(11) 2458-2465. Retrieved from http://www.biomedcentral.com/2458-2465. Accessed on 02/02/2012. 
